\title{
RELAÇÃO ENTRE COBERTURAS VEGETAIS E SUPRESSIVIDADE DE SOLOS A Rhizoctonia solani
}

\author{
RAQUEL GHINI' \& MARGARIDA M. H. ZARONI ${ }^{2}$
}

'Embrapa Meio Ambiente, Cx. Postal 69, CEP 13820-000 Jaguariúna, SP, fax: (019) 3867-8740, e-mail: raquel@cnpma.embrapa.br; ${ }^{2}$ Laboratório Regional de Apoio Animal, Cx. Postal 5538, CEP 13094-430 Campinas SP

(Aceito para publicação em 02/02/2001)

Autor para correspondência: Raquel Ghini

GHINI, R. \& ZARONI, M.M.H. Relação entre coberturas vegetais e supressividade de solos a Rhizoctonia solani. Fitopatologia Brasileira 26:10-15. 2001.

\section{RESUMO}

Áreas de uma microbacia sem a incidência de doenças causadas por Rhizoctonia solani GA 4 foram agrupadas estatisticamente, pelo método de Ward, com relação à supressividade dos solos ao patógeno, avaliada pela taxa de crescimento micelial. Entre os grupos formados, foi definido um gradiente de supressividade. A relação entre gradientes de supressividade e tipos de cobertura vegetal foi descrita com auxílio da análise de correspondências múltiplas, sendo que, de modo geral, o pasto e o pousio, seguidos da mata, tornaram os solos mais supressivos, ao passo que a cana-de-açúcar (Saccharum officinarum), o milho (Zea mays), o café (Coffea arabica) e o solo arado tornaram os solos mais conducentes. Porém, os resultados mostraram que outros fatores, além da cobertura vegetal, podem estar afetando a supressividade. Um tratamento biocida (fumigação) dos solos mais supressivos promoveu um maior incremento da taxa de crescimento do patógeno do que o observado com solos mais conducentes.

Palavras-chave: solo supressivo, solo conducente, análise de correspondências múltiplas, análise de agrupamento.

\section{Relationship between vegetation and soil suppressiveness to Rhizoctonia solani}

Areas from a microbasin without the incidence of plant diseases caused by Rhizoctonia solani GA 4 were statistically grouped by Ward's method, in relation to soil suppressiveness, described by the mycelial growth rate. A gradient of suppressiveness was defined between the groups. The relationship between suppressiveness and types of vegetation was described by a multiple correspondence analysis. In general, soils from pasture, fallow ground and forest were classified as suppressive soils, while sugar cane (Saccharum officinarum), maize (Zea mays), coffee (Coffea arabica) and ploughed soils, as conducive soils. However, results showed that other factors affect suppressiveness besides vegetation. A biocide treatment (fumigation) promoted a greater increase in the growth rate of the pathogen on suppressive soils than on conducive ones.

\section{INTRODUÇÃO}

A menor incidência de fitopatógenos habitantes do solo num dado campo, em comparação com áreas próximas, é um fato freqüentemente observado por agricultores. Entretanto, segundo Reis (1991), o fenômeno recebe pouca atenção por parte dos fitopatologistas que, de modo geral, dedicam maior atenção ao estudo de áreas onde estão ocorrendo danos econômicos às culturas. Nesses solos, denominados supressivos, segundo Baker \& Cook (1974), o desenvolvimento de doenças é suprimido, mesmo se o patógeno for introduzido na presença do hospedeiro suscetível.

Quando solos supressivos são identificados, deve-se estudar os fatores que determinam essa característica, para utilizar tais informações na indução de supressividade de solos problemáticos (Rodríguez-Kábana \& Calvet, 1994). A indução pode ser realizada por meio da incorporação de antagonistas ou estímulo da sua população, tratos culturais ou outras medidas de manejo.

Nos solos supressivos, segundo Baker \& Cook (1974), o patógeno: a) não se estabelece, b) se estabelece, mas não produz doença, ou c) se estabelece e causa doença por um determinado período, porém sofre um declínio com o tempo. No caso de Rhizoctonia solani Kuhn, segundo Hyakumachi (1996), os solo supressivos estão na primeira ou na última categoria. A primeira é também descrita como solos "supressivos ao patógeno", onde são importantes as características bióticas e abióticas dos solos. A última categoria pode ser descrita como "declínio da doença" e a supressividade pode ser biologicamente induzida pela monocultura.

Além da monocultura, diversos outros fatores afetam a supressividade a $R$. solani, tais como a população de 
Trichoderma no solo (Henis et al., 1979; Chet \& Baker, 1980; Liu \& Baker, 1980), microbiota do solo (Kobayashi \& Ko, 1985), tipo de solo, $\mathrm{pH}$ e umidade (Henis et al., 1979; Liu \& Baker, 1980). No Brasil, Pozzer \& Cardoso (1990) estudaram a supressividade natural de um latossolo vermelho-escuro e verificaram que a supressividade pode ser transferida para um solo conducente e foi reduzida com o tratamento térmico, comprovando o envolvimento da microbiota no fenômeno. Rodrigues et al. (1996) observaram supressividade natural a $R$. solani em alguns solos sob vegetação de cerrado e verificaram correlação da supressividade com o caráter álico, associado à textura argilosa dos solos. Michereff et al. (1996) verificaram efeitos do tipo de solo, níveis de alumínio trocável, pH e população de Trichoderma spp. no solo.

Os objetivos do presente trabalho foram determinar a similaridade da supressividade de solos a $R$. solani em diferentes tipos de coberturas vegetais, em áreas sem a incidência da doença, procurando estabelecer agrupamentos semelhantes quanto à taxa de crescimento do patógeno nos solos; e verificar as alterações da supressividade após a eliminação da microbiota, isto é, após um tratamento biocida. A microbacia foi definida como unidade fisiográfica para o desenvolvimento do trabalho, como forma de delimitar a área de estudo e por sua homogeneidade.

\section{MATERIAL E MÉTODOS}

\section{Coleta do solo}

As amostras de solo foram coletadas na microbacia do Córrego do Taquara Branca, localizada no Município de Sumaré, SP (Menk \& Miranda, 1997).

Cinqüenta e nove amostras de solos com diversas coberturas vegetais foram obtidas, aleatoriamente, na freqüência de seis amostras/coleta. Em cada local, sete subamostras de solo de $8 \times 8 \times 8 \mathrm{~cm}$ foram retiradas, homogeneizadas, peneiradas $(4 \mathrm{~mm})$ e submetidas às avaliações, até 24 h após a coleta.

\section{Supressividade a $R$. solani}

A supressividade dos solos foi avaliada por meio do crescimento de $R$. solani GA 4 [isolado de feijoeiroPhaseolus vulgaris $\mathrm{L}$.)], em placas de Petri (15 $\mathrm{cm}$ de diâmetro). Uma camada de solo, fumigado ou não, com a umidade corrigida para $70 \%$ da capacidade de campo, foi colocada nas placas de Petri (50 g/placa) e, a seguir, verteu-se uma fina camada de ágar-água sobre o solo, em três repetições.

A fumigação dos solos com clorofórmio isento de etanol foi o método escolhido por eliminar a microbiota sem a presença de resíduos (Brookes et al., 1982). Para tanto, as amostras de solo, contidas em recipientes de vidro, foram acondicionadas em dessecadores ( $30 \mathrm{~cm}$ de diâmetro), cujas paredes internas foram forradas com papel de filtro umedecido. Cada dessecador recebeu um Becker $(50 \mathrm{ml})$ contendo clorofórmio isento de etanol $(20 \mathrm{ml})$ e pérolas de vidro (3 mm de diâmetro). A aplicação de vácuo $(52 \mathrm{~cm} \mathrm{Hg})$ foi realizada para volatilização do clorofórmio por aproxi- madamente 20 min, sendo que o dessecador permaneceu fechado por $72 \mathrm{~h}$. Depois da fumigação, os dessecadores permaneceram abertos por, aproximadamente, $2 \mathrm{~h}$, para a completa evaporação do clorofórmio.

Discos contendo micélio de $R$. solani $(7 \mathrm{~mm}$ de diâmetro) foram transferidos para o centro das placas e a incubação foi realizada a $25^{\circ} \mathrm{C}$, no escuro. A testemunha foi constituída pelo crescimento do fungo em placas de Petri contendo ágar-água.

Diariamente, foram avaliados dois diâmetros perpendiculares da colônia de $R$. solani, com auxílio de microscópio estereoscópico.

\section{Análise estatística}

O dispositivo de ramos e folhas (Tukey, 1977) e a análise de agrupamento pelo método de Ward (Everitt, 1981) foram utilizados para descrever padrões de similaridade mútua entre as coberturas vegetais, quanto à supressividade do solo a $R$. solani (solos não fumigados). Para a supressividade, utilizou-se a taxa diária de crescimento micelial do patógeno $(\mathrm{cm} / \mathrm{dia})$ nos 60 pontos amostrais, onde foram observados 12 tipos de coberturas vegetais [cana-de-açúcar (Saccharum officinarum L.), mata, pasto, tomate (Lycopersicon esculentum Mill.), feijão (Phaseolus vulgaris L.), milho (Zea mays L.), batata (Solanum tuberosum L.), café (Coffea arabica L.), couve-flor (Brassica oleracea var. botrytis L.), goiaba (Psidium guajava L.), pousio, solo arado sem cobertura vegetal).

Os 12 tipos de coberturas vegetais foram associados através da análise de correspondências múltiplas (Escofier \& Pagé, 1988) à supressividade do solo a $R$. solani. As matrizes de dados geradas foram processadas utilizando-se o Sistema de Análises Estatísticas (SAS, 1986, na versão 6.03).

Com o objetivo de avaliar os efeitos da eliminação da microbiota na supressividade, ou seja, comparar a supressividade das amostras de solo fumigadas ou não, foi criada a variável "Porcentagem de incremento da taxa de crescimento de $R$. solani após a fumigação" e analisada graficamente em função dos padrões empíricos de similaridade observados nas amostras sem fumigação. A variável foi definida como:

$$
\text { \%incremento }=\frac{y-x}{x} \times 100
$$

onde $x=$ taxa de crescimento no solo não fumigado e $y=$ taxa de crescimento no solo fumigado.

\section{RESULTADOS E DISCUSSÃO}

\section{Similaridade da supressividade de solos a $R$. solani em diferentes tipos de coberturas vegetais}

No dispositivo de ramos e folhas, a distribuição de frequiência da variável taxa de crescimento micelial de $R$. solani em solo não fumigado apresentou um caráter multimodal, demonstrando que, provavelmente, existem 
grupos de coberturas vegetais com distribuições de frequência diferentes, quanto à supressividade do solo ao patógeno (Figura 1). Com a aplicação da Análise de Agrupamentos sobre a variável, foram obtidos seis grupos distintos de supressividade, explicando 96\% da variância total (Tabela 1). Empiricamente, esses grupos foram representados da maior supressividade à maior conducência, respectivamente, por +++ supressivo, ++supressivo, até ++ conducente e +++ conducente, sendo tal classificação comparativa dentro do universo amostral do trabalho. Os valores médios, máximos e mínimos da taxa de crescimento micelial para cada grupo mostram que eles representam grupos distintos quanto ao

\begin{tabular}{|r|lc|}
\hline \multicolumn{2}{|c|}{ Ramos e folhas } & Frequência \\
\hline 36 & 8 & 1 \\
34 & 40 & 2 \\
32 & 2345223 & 7 \\
$\mathbf{3 0}$ & $\mathbf{2 3 5 6 0 1 2 6 9}$ & 9 \\
28 & 4048 & 4 \\
$\mathbf{2 6}$ & $\mathbf{2 3 7 7 0 3 7 8 8}$ & 9 \\
24 & 178 & 3 \\
$\mathbf{2 2}$ & $\mathbf{0 0 0 1 2 7 9}$ & 7 \\
20 & 681 & 3 \\
$\mathbf{1 8}$ & $\mathbf{5 5 1 1 3 4}$ & 6 \\
16 & 6 & 1 \\
14 & 4 & 1 \\
$\mathbf{1 2}$ & $\mathbf{6 3 4}$ & 3 \\
10 & 9 & 1 \\
8 & 6 & 1 \\
6 & 7 & 1 \\
\hline
\end{tabular}

FIG. 1 - Dispositivo de ramos e folhas da variável taxa de crescimento micelial $\left(10^{-1} \mathrm{~cm} /\right.$ dia $)$ de Rhizoctonia solani.

TABELA 1 - Caracterização dos agrupamentos ${ }^{(1)}$ de supressividade a Rhizoctonia solani em solos não fumigados, taxas médias, mínimas e máximas de crescimento micelial, desvio padrão e coeficiente de variação (C.V.)

\begin{tabular}{cccccc}
\hline \hline \multirow{2}{*}{ Supressividade } & \multicolumn{3}{c}{$\begin{array}{c}\text { Taxa de crescimento } \\
\text { micelial (cm/dia) }\end{array}$} & $\begin{array}{r}\text { Desvio } \\
\text { padrão }\end{array}$ & $\begin{array}{c}\text { C.V. } \\
\text { (\%) }\end{array}$ \\
\cline { 2 - 4 } & Média & Mínima & Máxima & & \\
\hline +++ supressivo & 0,94 & 0,77 & 1,09 & 0,16 & 17,05 \\
++ supressivo & 1,43 & 1,26 & 1,66 & 0,17 & 11,79 \\
+ + supressivo & 2,02 & 1,85 & 2,20 & 0,14 & 6,74 \\
+ conducente & 2,57 & 2,31 & 2,78 & 0,17 & 6,69 \\
++ conducente & 3,01 & 2,84 & 3,12 & 0,09 & 2,97 \\
+++ conducente & 3,32 & 3,16 & 3,68 & 0,15 & 4,48 \\
\hline
\end{tabular}

(1) A análise de agrupamentos foi feita utilizando-se o método de Ward (Everitt, 1981) crescimento do patógeno, sendo que, por exemplo, o grupo +++supressivo apresenta uma taxa diária de crescimento micelial, aproximadamente, três vezes menor do que a apresentada pelo grupo +++conducente (Tabela 1). Ko \& Ho (1983) também observaram que o crescimento de $R$. solani diferiu significativamente em 30 amostras de solo, sendo obtidos crescimentos lineares que variavam de 10 a $130 \mathrm{~mm}$ em seis dias; porém, os solos foram classificados em apenas duas categorias, sendo que os supressivos inibiam $50 \%$ do crescimento observado nos solos conducentes.

Da aplicação da análise de correspondências múltiplas, as coberturas vegetais foram classificadas em quatro grupos quanto a supressividade ao patógeno (Tabela 2). O grupo formado pelo pasto e o pousio teve taxa média de crescimento micelial de 1,91 cm/dia. O formado pela mata e a batata teve taxa média de crescimento micelial de $2,15 \mathrm{~cm} / \mathrm{dia}$. O formado pela couve-flor, goiaba, tomate e feijão teve taxa média de crescimento micelial de $2,65 \mathrm{~cm} / \mathrm{dia}$. E o formado pela cana, milho, café e solo arado teve taxa média de crescimento micelial de 2,88 cm/dia. Esses grupos foram nomeados de RS1, RS2, RS3 e RS4, respectivamente. As taxas médias de crescimento micelial, como resultado da análise de correspondências múltiplas, foram representadas no biplano da Figura 2, por pontos de mesmo nome, apresentando um comportamento não linear entre os dois eixos principais. Portanto, a supressividade do solo passa de mais supressiva a mais conducente do sentido positivo para o negativo do primeiro eixo principal. Mas existe um contraponto no segundo eixo principal, entre o que foi denominado RS1 (lado positivo) e RS3 (lado negativo), tornando essa tendência não linear. Tal efeito foi devido ao fato de que dentro de um mesmo grupo, as mesmas coberturas vegetais, em diferentes pontos amostrais, apresentaram variações nas taxas de crescimento do patógeno. Mas as estatísticas descritivas (Tabela 2) mostram que houve sempre uma grande concentração dos valores das taxas de crescimento em torno da média e mediana que têm valores próximos, e que somente em alguns casos os valores das taxas se mantiveram longe da concentração. Por exemplo, o pasto, em média tem baixa taxa de crescimento do patógeno, mediana de 1,85 cm/dia, ou seja, $50 \%$ dos solos observados tem taxa menor que este valor, mas alguns pontos amostrais observados atingiram taxas classificadas em +++ conducentes. A cana, classificada no grupo RS4, tem em média alta taxa de crescimento do patógeno, mas tem pontos amostrais dispersos entre ++ supressivos e +++ conducentes. Isso significa que outros fatores, além da cobertura vegetal, implicaram no aumento ou decréscimo da supressividade. Assim, só a cobertura vegetal não é suficiente para explicar que um solo é mais supressivo ou mais conducente. Esse resultado está de acordo com diversos outros trabalhos que comprovam os efeitos de vários fatores bióticos e abióticos na supressividade de solos a $R$. solani (Henis et al., 1979; Chet \& Baker, 1980; Liu \& Baker, 1980; Kobayashi \& Ko, 1985; Pozzer \& Cardoso, 1990; Rodrigues et al., 1996; Michereff et al., 1996).

Em termos gerais, o pasto e o pousio (RS1), seguidos 
TABELA 2 - Distribuição de frequência de coberturas vegetais — classificadas em 4 grupos pela aplicação da Análise de Correspondências Múltiplas — segundo os agrupamentos de supressividade do solo a Rhizoctonia solani em solos não fumigados e estatísticas descritivas da taxa de crescimento micelial (cm/dia) de $R$. solani, por grupo de cobertura vegetal.

\begin{tabular}{|c|c|c|c|c|c|c|c|c|c|c|c|c|}
\hline \multirow[b]{2}{*}{ Supressividade } & \multicolumn{2}{|c|}{ RS1 } & \multicolumn{2}{|c|}{ RS2 } & \multicolumn{4}{|c|}{ RS3 } & \multicolumn{4}{|c|}{ RS4 } \\
\hline & Pasto & Pousio & Mata & Batata & $\begin{array}{c}\text { Couve } \\
\text {-flor }\end{array}$ & Goiaba & Tomate & Feijão & Cana & Milho & Café & $\begin{array}{c}\text { Solo } \\
\text { arado }\end{array}$ \\
\hline+++ supressivo & 2 & 0 & 1 & 0 & 0 & 0 & 0 & 0 & 0 & 0 & 0 & 0 \\
\hline ++ supressivo & 2 & 1 & 1 & 0 & 0 & 0 & 0 & 0 & 1 & 0 & 0 & 0 \\
\hline + supressivo & 3 & 0 & 4 & 1 & 0 & 0 & 1 & 2 & 2 & 0 & 0 & 0 \\
\hline+ conducente & 1 & 0 & 3 & 0 & 1 & 1 & 3 & 3 & 4 & 0 & 0 & 0 \\
\hline ++conducente & 0 & 0 & 1 & 0 & 0 & 0 & 1 & 0 & 2 & 3 & 1 & 3 \\
\hline+++ conducente & 2 & 0 & 0 & 0 & 0 & 0 & 1 & 1 & 5 & 2 & 0 & 1 \\
\hline Total & 10 & 1 & 10 & 1 & 1 & 1 & 6 & 6 & 14 & 5 & 1 & 4 \\
\hline média & \multicolumn{2}{|c|}{1,91} & \multicolumn{2}{|c|}{2,15} & \multicolumn{4}{|c|}{2,65} & \multicolumn{4}{|c|}{2,88} \\
\hline mediana & \multicolumn{2}{|c|}{1,85} & \multicolumn{2}{|c|}{2,20} & \multicolumn{4}{|c|}{2,67} & \multicolumn{4}{|c|}{3,06} \\
\hline moda & \multicolumn{2}{|c|}{0,77} & \multicolumn{2}{|c|}{0,96} & \multicolumn{4}{|c|}{1,93} & \multicolumn{4}{|c|}{3,31} \\
\hline 1o. quartil & \multicolumn{2}{|c|}{1,26} & \multicolumn{2}{|c|}{1,91} & \multicolumn{4}{|c|}{2,37} & \multicolumn{4}{|c|}{2,63} \\
\hline 3o. quartil & \multicolumn{2}{|c|}{2,60} & \multicolumn{2}{|c|}{2,47} & \multicolumn{4}{|c|}{2,78} & \multicolumn{4}{|c|}{3,25} \\
\hline $\mathrm{CV}(\%)$ & \multicolumn{2}{|c|}{43,98} & \multicolumn{2}{|c|}{25,16} & \multicolumn{4}{|c|}{16,55} & \multicolumn{4}{|c|}{18,78} \\
\hline mínimo & \multicolumn{2}{|c|}{0,77} & \multicolumn{2}{|c|}{0,96} & \multicolumn{4}{|c|}{1,93} & \multicolumn{4}{|c|}{1,33} \\
\hline máximo & \multicolumn{2}{|c|}{3,33} & & 2,90 & & & 45 & & & 3,6 & & \\
\hline
\end{tabular}

da mata (RS2), acarretaram solos supressivos, ao passo que a cana, o milho, o café e o solo arado (RS4) acarretaram solos conducentes. Tal resultado pode estar associado ao sistema de cultivo e ao tempo de permanência de cada cultura no campo, haja visto que, segundo Schneider (1982), solos supressivos são comuns em ambientes ecologicamente balanceados de ecossistemas em clímax, nos quais os constituintes físico-químicos e microbianos do solo tiveram anos para estabilizar. Tanto o pasto, quanto o pousio e a mata, estavam há vários anos sem as alterações causadas pelas práticas agrícolas que ocorreram, por exemplo, nos solos cultivados com cana, café ou nos solos arados.

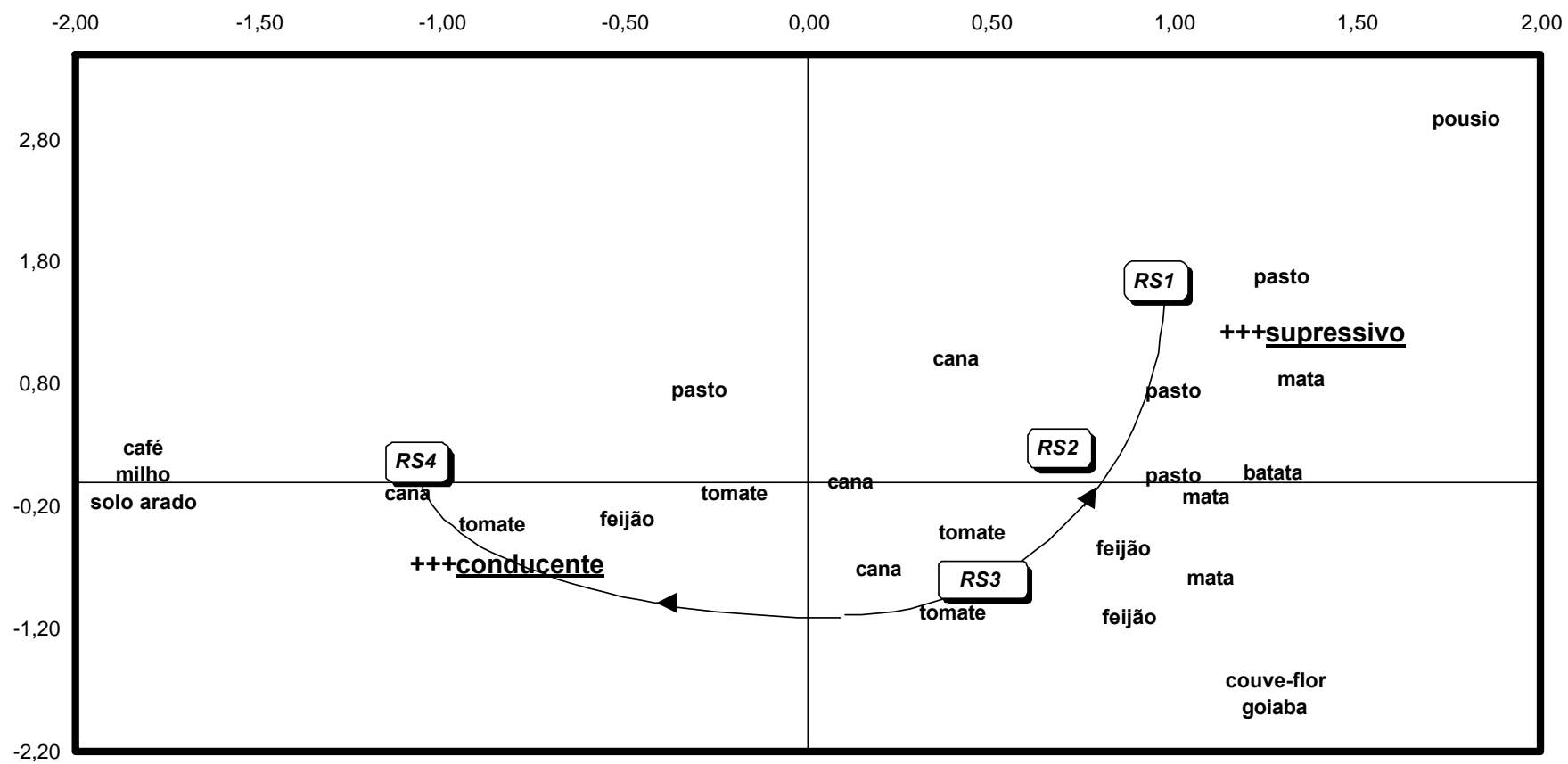

FIG. 2 - Representação no biplano das coberturas vegetais associadas a supressividade do solo a Rhizoctonia solani, em solos não fumigados, pela Análise de Correspondências Múltiplas, representadas pelos pontos RS1, RS2, RS3 e RS4. 
O plano amostral com caráter aleatório, isto é, baseado no sorteio aleatório dos pontos amostrais, caracterizou o presente trabalho. Por isso, algumas coberturas vegetais ocorreram com maior freqüência, haja vista que são predominantes na área. Como o objetivo do trabalho foi determinar a similaridade da supressividade de solos com diferentes coberturas vegetais, as ocorrências obtidas foram consideradas como indicadoras de supressividade. Assim sendo, com os resultados obtidos foram geradas ferramentas para o desenvolvimento de novos estudos para a padronização de categorias de supressividade ou mapeamento de áreas ou estudos com grupos de coberturas vegetais. Outros testes com os fatores bióticos ou abióticos que afetam a supressividade desses solos são necessários para a indução de supressividade em solos problemáticos.

\section{Incremento da taxa de crescimento micelial de $R$. solani após a fumigação.}

A fumigação dos solos resultou na redução da supressividade, ou seja, um aumento na taxa de crescimento do patógeno. A porcentagem de incremento da taxa após a fumigação foi decrescente de solos +++ supressivos a +++ conducentes (Figura 3). Isto é, em solos mais supressivos, a porcentagem média de incremento da taxa de crescimento foi maior do que para solos mais conducentes. Isso significa que a eliminação da microbiota do solo pela fumigação reduziu a supressividade dos solos mais supressivos e teve pouco efeito nos solos conducentes, chegando a ter um incremento negativo nesse grupo. A importância da microbiota na supressividade a $R$. solani também foi demonstrada por Ghini et al. (1998), que utilizando amostras de solo da microbacia do Córrego do Taquara Branca, encontraram alta correlação entre a supressividade a $R$. solani e a atividade microbiana do solo, avaliada pela hidrólise de diacetato de fluoresceina (FDA) e pelo desprendimento de $\mathrm{CO}_{2}$. Dessa forma, a manutenção ou

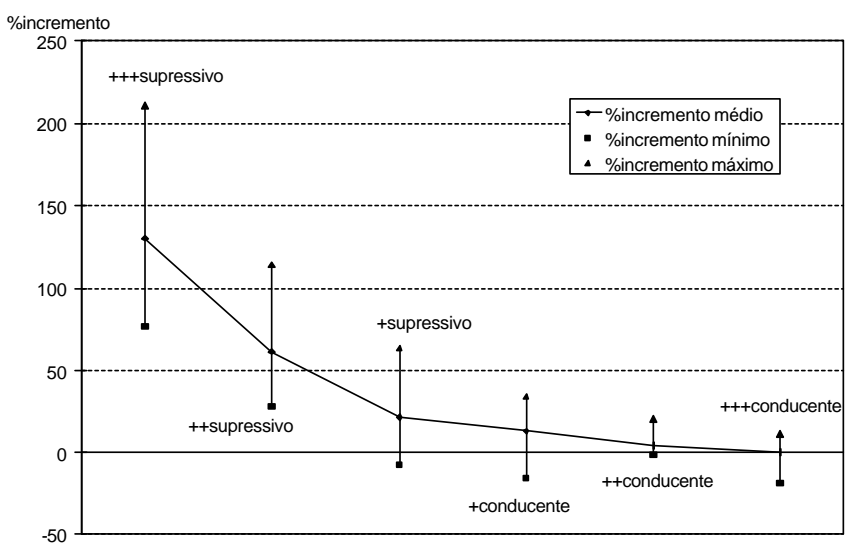

FIG. 3 - Porcentagem de incremento da taxa de crescimento micelial de Rhizoctonia solani após a fumigação, comparada ao crescimento no solo não fumigado, para os diferentes grupos de supressividade ao patógeno $(+++$ supressivo até +++ conducente). estímulo da atividade microbiana do solo é uma importante medida no manejo da doença.

A perda de supressividade a $R$. solani, após um tratamento biocida, também foi observada por Nelson \& Hoitink (1983), Pozzer \& Cardoso (1990) e Gorodecki \& Hadar (1990) que utilizaram tratamento térmico e radiação gama. O método de fumigação apresentado por Brookes et al. (1982) para determinação da biomassa P do solo, usado no presente trabalho, se mostrou eficiente, não interferindo com a presença de resíduos que pudessem inibir o crescimento do patógeno.

\section{AGRADECIMENTOS}

As autoras agradecem ao Engenheiro Agrônomo José Abrahão Haddad Galvão pela coleta das amostras de solo; à Assistente de Operações Mara Denise Luck Mendes pela realização dos ensaios; e ao Prof. Dr. Paulo Cezar Ceresine pela classificação do patógeno.

\section{REFERÊNCIAS BIBLIOGRÁFICAS}

BAKER, R. \& COOK, J. Biological control of plant pathogens, San Francisco. W. H. Freeman, 1974.

BROOKES, P.C., POWLSON, D.S. \& JENKINSON, D.S. Measurement of microbial biomass phosphorus in soil. Soil Biology and Biochemistry 14:319-329. 1982.

CHET, H. \& BAKER, R. Induction of suppressiveness to Rhizoctonia solani in soil. Phytopathology 70:994998.1980.

ESCOFIER, B. \& PAGÈS, J. Analyses factorielles simples et multiples. Objectifs, méthodes et interpretation. Dunod, Paris, 1988.

EVERITT, B. Cluster Analysis. 2a. ed. New york, Wiley, 1981.

GHINI, R., MENDES, M.D.L. \& BETTIOL, W. Utilização do método de hidrólise de diacetato de fluoresceina (FDA) como indicador de atividade microbiana no solo e supressividade a Rhizoctonia solani. Summa Phytopathologica 24:239-242. 1998.

GORODECKI, B. \& HADAR, Y. Suppression of Rhizoctonia solani and Sclerotium rolfsii diseases in container media containing composted separated cattle manure and composted grape marc. Crop Protection 9:271-274. 1990.

HENIS, Y., GRAFFAR, A. \& BAKER, R. Factors affecting suppressiveness to Rhizoctonia solani in soil. Phytopathology 69:1164-1169. 1979.

HYAKUMACHI, M. Suppression and prevention in Rhizoctonia disease: mechanisms involved in disease decline. Anais: V SICONBIOL, Conferências e Palestras, Foz do Iguaçu, PR. 1996. pp.140-149.

KO, W.H. \& HO, W.C. Screening soils for suppressiveness to Rhizoctonia solani and Pythium splendens. Annals Phytopathological Society of Japan 49:1-9. 1983.

KOBAYASHI, N. \& KO, W.H. Nature of suppression of Rhizoctonia solani in hawaiian soils. Transactions of British Mycological Society 84:691-694. 1985. 
LIU, S. \& BAKER, R. Mechanism of biological control in soil supressive to Rhizoctonia solani. Phytopathology 70:404-412.1980.

MENK, J.R.F. \& MIRANDA, J.I. Levantamento pedológico e mapeamento do risco de erosão dos solos da Microbacia do Córrego Taquara Branca, Sumaré, SP. Jaguariúna: EMBRAPA-CNPMA, 1997.

MICHEREFF FILHO, M., MICHEREFF, S.J., SILVA, E.B., ANDRADE, D.E.G.T., ANTUNES SOBRINHO, S. \& MARIANO, R.L.R. Influência de tipos de solo do estado de Pernambuco na intensidade de doença induzida por Rhizoctonia solani em feijoeiro. Fitopatologia Brasileira 21:19-25.1996.

NELSON, E.B. \& HOITINK, H.A.J. The role of microorganisms in the suppression of Rhizoctonia solani in container media amended with composted hardwood bark. Phytopathology 73:274-278, 1983.

POZZER, L. \& CARDOSO, J.E. Supressividade natural de um latossolo vermelho-escuro a Rhizoctonia solani. Fitopatologia Brasileira 15:206-210.1990.
REIS, E.M. Solos supressivos e seu aproveitamento no controle de doenças de plantas. In: BETTIOL, W. (Ed.) Controle biológico de Doenças de Plantas. EMBRAPACNPMA, 1991. pp.181-193.

RODRIGUES, F. de A., CORRÊA, G.F., SANTOS, M.A. dos, BORGES FILHO, E.L. Fatores envolvidos na supressividade à Rhizoctonia solani em alguns solos tropicais sob vegetação natural. Anais, $13^{\mathrm{o}}$ Congresso Latino Americano de Ciência do Solo, Águas de Lindóia, SoloSuelo 96. Campinas: SBCS, Piracicaba: ESALQ-USP, 1996. CD-ROM.

RODRIGUEZ-KABANA, R. \& CALVET, C. Capacidad del suelo para controlar enfermidades de origen edafico. Fitopatologia Brasileira 19:129-138.1994.

SAS. Statistical Analysis Systems, version 6.02. North Caroline: SAS Institute Inc, 1986. Disquete $31 / 2$ ".

SCHNEIDER, R.W. Suppressive soils and plants. APS Press, St. Paul, 1982.

TUKEY, J.W. Exploratory Data Analysis. Addison Wesley, Reading, Massachusetts, 1977. 